\title{
SACI, DE MONTEIRO LOBATO: UM MITO NACIONALISTA
}

\author{
Míriam Stella Blonski*
}

RESUMO:

Este trabalho tem como objetivo destacar o inquérito realizado por Monteiro Lobato, através do jornal 0 Estado de São Paulo, e publicado em 1918 com o título: 0 Sacy-Pererê resultado de um inquérito. Além disso, visa focalizar o mito do Saci, privilegiado por Lobato em sua obra, procurando chamar a atenção dos brasileiros para as raizes culturais do Brasil, buscando preservar sua identidade. Esse trabalho estendeu-se ao público infanto-juvenil, com a publicação, em 1921, do livro 0 Saci, inscrito no universo do Sítio do Picapau Amarelo.

PALAVRAS-CHAVE: Monteiro Lobato, saci, caboclo, cultura.

\begin{abstract}
Monteiro Lobato foi um sonhador. Sonhou um Brasil progressista, transformador das realidades adversas que assolavam o País, como a doença e a verminose, a miséria econômica, especialmente entre as populações rurais. Empunhando suas grandes armas que eram o entusiasmo e a palavra, lança-se também em campanhas em prol do ferro e do petróleo nacionais, capazes, na opinião do escritor, de proporcionar aos brasileiros o progresso material de que necessitavam para vencerem os seus problemas. Acreditava ele, também, que era necessário descobrir e conquistar aquilo que constituía o cerne do povo, sua força, sua razão maior: a sua brasilidade. Essa brasilidade podia ser traduzida, entre outras idéias, pelo rompimento com as influências estrangeiras, principalmente européias, e pela busca de autenticidade e pureza nas manifestações do povo. Segundo Lobato, era preciso acordar os brasileiros, demovê-los da prática nociva de camuflar os problemas do país, de enfeitar a desgraça, levando-os às atitudes positivas de buscar e praticar tentativas de solução para esses mesmos problemas.
\end{abstract}

* Mestre em Letras: Estudos Literários (Área de concentração: Literatura Brasileira), 2003. 


\section{EMTESE}

Belo Horizonte, v. 8, p. I-243, dez. 2004

0 pioneirismo de Monteiro Lobato o fez privilegiar o Saci-Pererê como símbolo do espírito nacional, uma espécie de produto da fantasia imaginativa das três raças formadoras do povo brasileiro, importante mito da Cultura Popular e do Folclore.

0 Saci inscreve-se num tema que pertence às raízes e ao patrimônio cultural do Brasil. Sua função é, principalmente, contribuir para a preservação da cultura brasileira.

Ao resgatar o mito do Saci-Pererê, Monteiro Lobato o cerca de características brasileiras, utilizando não apenas suas próprias pesquisas, mas os depoimentos que obteve por ocasião do inquérito realizado através do jornal 0 Estado de São Paulo. Nesse momento, preocupado com o nosso desenraizamento cultural, resgata para o povo urbano a sua consciência original, que se encontrava enfraquecida em decorrência da grande infiltração das idéias européias.

0 ano de 1917, em que Lobato realiza o inquérito sobre o Saci, que recebeu o nome de "Mitologia Brasílica - Inquérito sobre o Saci-Pererê", apresentanos um quadro de crescimento das cidades, de industrialização ascendente, fazendo surgir categorias profissionais típicas das zonas urbanas, como operários, profissionais liberais, militares, etc. provocando, cada vez mais, o afastamento das atenções, do cenário rural. Fazendeiros, colonos e sitiantes dirigiam-se para a cidade, em busca de oportunidades de trabalho. Enquanto isso, esquecido e isolado nos rincões do país, permanecia um tipo rústico, até certo ponto puro, que não se deixava contaminar pelas influências da vida urbana: o caboclo. Em sua autenticidade, mantinha-se fiel à cultura caipira, cujos ensinamentos the foram legados através dos seus ancestrais, e que ele continuava praticando e transmitindo aos filhos. Como parte da sua cultura podemos citar as crendices, as superstições, os mitos nos quais ele acreditava, e entre eles, o Saci-Pererê.

0 cenário acima descrito propicia o fortalecimento, nas letras e nas artes, de um sertanismo nostálgico, que focaliza a vida rural como modelo idealizado de sociedade a ser preservado. Lobato não se mantém alheio a essa tendência, e concentra sua atenção no caboclo, personalizado pela figura do Jeca Tatu. Se, anteriormente, o escritor o descrevera como "selvagem, arredio, desconfiado, piolho da terra, parasita funesto, preguiçoso e maligno, inadaptável à civilização", agora ele refaz sua opinião, passando a elogiar as qualidades do caboclo, tornando-se, dessa forma, seu aliado. 
0 inquérito de Monteiro Lobato, que obteve grande repercussão na época, foi constituído de vários depoimentos, reunidos pelo escritor em livro com cerca de 300 páginas e tiragem inicial de dois mil exemplares.

A capa do livro é vermelha, simbolicamente da cor do sangue, do fogo, e também do amor. Segundo o Dicionário de Símbolos, é a cor de Dioniso. Dioniso e também o demônio são representados comumente com chifres, símbolo da força e do poder. Provavelmente por essa razão, José Washt Rodrigues, autor do desenho do Saci que nela aparece, optou por apresentá-10 com essa característica: chifres curvos. Na cabeça tem o gorro vermelho, olhos também vermelhos e a boca apresentando dentes serrilhados, ponteagudos, vampirescos, numa alusão provável ao hábito do Saci de sugar o sangue dos cavalos. Sua expressão pode ser interpretada como irônica, zombeteira, e até um pouco maléfica. Tem o corpo de adulto, com uma perna só. Os dedos dos pés são apresentados abertos, mais animalescos do que humanos. Também podem ter sido apresentados dessa forma pelo hábito de andar sempre descalço e por longas caminhadas, o que deforma os dedos, engrossando-os e aumentando o espaço de um para o outro. Numa das mãos carrega uma espécie de pau, uma possível arma com que desfere bordoadas tanto em pessoas como em animais. Na outra mão, prende o costumeiro cachimbo aceso, fumegante. Ao seu redor folhas e traços que dão a impressão de movimento circular, como nos rodamoinhos, e também simbolizando o corpo em movimento. Esse desenho é coerente não apenas com as descrições dos relatos sobre o Saci, que constam nos depoimentos do corpo do livro, mas também remete-nos novamente à mitologia, tanto com Dioniso como também com faunos e com Pã. (Figura 1)

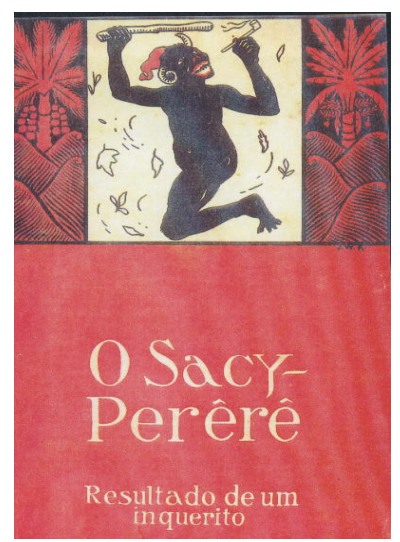

Figura 1 


\section{EMTESE}

Belo Horizonte, v. 8, p. I-243, dez. 2004

Lobato faz duas dedicatórias na abertura do livro. A primeira delas, em tom de sarcasmo, é para o "Bar Trianon", local onde se reunia, em São Paulo, a elite do Estado, que absorvia a cultura européia, sem sequer cogitar em levar em consideração e muito menos praticar as variadas formas das riquezas culturais brasileiras. Esta primeira dedicatória reflete bem a intenção inicial de Lobato com o Inquérito, ou seja, combater a invasão do "francesismo" e de tudo o que descaracterizasse o elemento nacional. A segunda, num tom carinhoso, reconhecido e saudoso, é para a tia Esméria, e "de quanta preta velha nos pôs, em criança, de cabelos arrepiados com histórias de cucas, sacis e lobisomens..." Tia Esméria foi empregada na fazenda do pai do escritor, e freqüentemente contava histórias para a criançada, nas quais as personagens folclóricas eram presença obrigatória. Também aqui o escritor reforça seu combate, criticando o novo costume da sociedade, de entregar o cuidado dos seus filhos às governantas, muito bem pagas, denominadas por ele de "lambisgóias de touca branca, numa algaravia teuto-itálico-nipônica". A função dessas governantas era, também, educar as crianças, "civilizá-las" conforme os costumes e cultura estrangeiros, daí a revolta de Lobato.

As inúmeras cartas recebidas vieram de todo o país, mas principalmente de São Paulo, Rio de Janeiro e Minas Gerais. Os missivistas eram pessoas que residiam tanto na zona rural quanto na zona urbana, alguns demonstrando cultura e erudição, outros se expressando de maneira simples, às vezes com o linguajar próprio do caboclo, eivado de expressões peculiares, fornecendo dados e descrições do Saci. Também houve a participação de negros ex-escravos e mesmo de seus descendentes. Até depoimentos de colonos italianos foram recebidos, o que comprova, em primeira análise, o conhecimento do assunto e a penetração do tema em várias camadas sociais, permanecendo vivo na lembrança das pessoas. Com os depoimentos ficou provado que as figuras míticas impregnam o imaginário do povo, especialmente dos habitantes de cidades do interior e da zona rural, mas também vivem entre os habitantes urbanos, fazendo parte de sua história de vida.

A publicação do livro representou uma espécie de depoimento-denúncia de reafirmação da sua luta nacionalista, que se serviu, nesse caso, dos relatos dos depoimentos para estimular o nascimento de uma consciência nacional, ao mesmo tempo em que alertava para que se prestasse mais atenção no caboclo, desconhecido das 
populações citadinas e litorâneas, e na legitimidade do Saci-Pererê como representante significativo dos mitos, no Brasil.

0 caboclo foi destacado por Lobato através da personagem Jeca-Tatu, uma espécie de símbolo do brasileiro, imagem do povo do interior. É preciso conhecer o povo, para melhor educá-10. Quando ele se revela através de suas manifestações culturais, e entre elas as superstições, as lendas como a do Saci, está fornecendo elementos que possibilitarão idéias e estratégias para uma ação educativa que parta das suas reais condições e necessidades. 0 Jeca Tatu é seu representante autêntico, imune às influências que não sejam as dos seus pares e as do ambiente em que vive. Quando a tristeza The corrói a alma, toma o violão e entoa as canções que 0 sentimento the dita. Tem a natureza, a mata e a simplicidade como suas companheiras. Identifica-se com elas, compreende-as, interpreta-as. Ao cair da noite, quando o silêncio impera, se o caboclo ouve um ruído que não identifica, logo the vem a suspeita de que se trata de algo acima de sua compreensão. Nesse momento fala o medo, fala o sobrenatural: "É o Saci!" E o seu olhar percorre o ambiente à procura da cruz, presa no batente da porta.

A importância do Inquérito sobre o Saci, realizado por Monteiro Lobato, é atestada por vários escritores e estudiosos em geral. Entre eles, pode-se mencionar o antropólogo e folclorista Luís da Câmara Cascudo, que assim se expressa:

Quando se fala no Saci sabe-se do "inquérito" que Monteiro Lobato dirigiu e que resultados extensos denunciou para a existência fantástica do duende negrinho.

Com o Sacy-Pererê - resultado de um inquérito, Lobato apresentou aos brasileiros um mito com características ora demoníacas, ora cruéis, perpassadas por manifestações de ironia, de deboche e até mesmo laivos de bondade. Um perfil bastante variado, e, até certo ponto, controverso, que the fora apresentado nas diversas correspondências recebidas. Embora esse livro não tenha sido reeditado pelo escritor, o tema se manteve presente no seu pensamento. Anos mais tarde ele volta ao assunto, desta vez na sua obra infantil. Era necessário incentivar nos jovens o entusiasmo e a dedicação às causas brasileiras e ao País, o culto pelas origens e o amor pela terra, com destaque para a vida na zona rural, no campo, tão importante quanto a vida urbana. Desta forma, destacava-se também o homem que lá 


\section{EMTESE}

Belo Horizonte, v. 8, p. I-243, dez. 2004

vivia, o caboclo, em continuidade às idéias defendidas anteriormente. No interior agreste habitava a lenda, a fantasia, o maravilhoso, a mula-sem-cabeça, e onde, às sextas-feiras de noite escura, podia surgir das trevas o lobisomem. Podia aparecer, ainda, cortando o vento e à garupa de um cavalo, o Saci-Pererê, iluminando a noite com seu capuz vermelho e com a brasa acesa do seu cachimbo.

Monteiro Lobato, no livro O Saci, publicado pela primeira vez em 1921, recria a personagem, suavizando-a. 0 nosso herói aparece, agora, com estatura de criança e atitudes brincalhonas, travessas. Suas peripécias são vividas no Sítio do Picapau Amarelo. A história é dividida em vinte e oito capítulos e narra desde a chegada de Pedrinho ao sítio, para passar as férias, seu encontro e aventuras com - Saci, até o encantamento de Narizinho, convertida em pedra pela Cuca, e o seu posterior desencantamento. Todos os episódios são mesclados pelo surgir de outros mitos folclóricos, acompanhados da respectiva explicação, muitas vezes pormenorizada pelo próprio Saci, que ocupa o papel de regente principal dos acontecimentos. Este papel o coloca na posição de herói, de certa forma reabilitando-o de ações maléficas que os depoimentos do Inquérito lhe atribuíam, e mesmo das pequenas diabruras que fazia. Monteiro Lobato, desta forma, lembra-nos a dualidade bem/mal existente nas criaturas, bem como a possibilidade da retratação do mal através dos atos generosos, das boas ações. Coloca o Saci, inclusive, numa categoria privilegiada entre os mitos no Brasil. Justifica-se, assim, não apenas sua curiosidade ligada às memórias da infância, mas também o interesse do adulto estudioso e pesquisador.

0 processo de suavização da imagem do Saci-Pererê é iniciado por Monteiro Lobato não apenas na síntese da descrição do moleque, que acontece no livro 0 SacyPererê - resultado de um inquérito, mas também no desenho a nanquim que ele faz, e que retrata o capetinha numa versão de criança, sem chifres, sem o porrete e com expressão observadora, desconfiada. Não tem mais aquela aparência cruel ou ameaçadora. 0 pitinho permanece, e os pés adquirem o formato humano. Essa modificação deveu-se, provavelmente, ao fato de que o livro 0 Saci é destinado, prioritariamente, para crianças, e o autor não tinha intenção de atemorizá-1as. (Figura 2)

Além de recriar a personagem, Monteiro Lobato descreve-a, servindo-se do negro velho, Tio Barnabé, personagem do Sítio do Picapau Amarelo, conhecedor dos mistérios que cercam o homem rural. Tio Barnabé assim fala do Saci: 


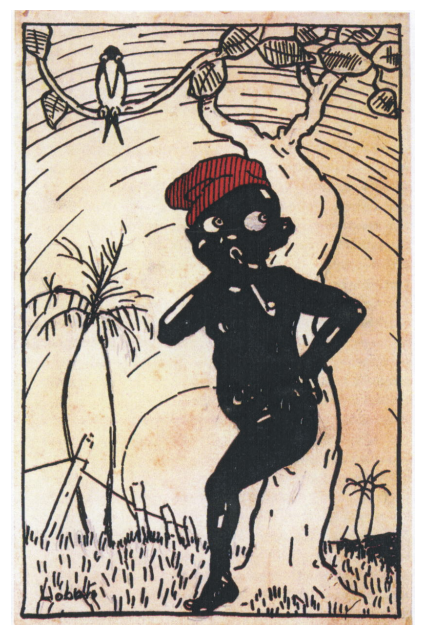

Figura 2

O Saci - começou ele - é um diabinho de uma perna só que anda solto pelo mundo, armando reinações de toda sorte e atropelando quanta criatura existe ... Azeda o leite, quebra a ponta das agulhas, esconde as tesourinhas de unha, embaraça os novelos de linha, faz o dedal das costureiras cair nos buracos, bota moscas na sopa, queima o feijão que está no fogo, gora os ovos das ninhadas. Quando encontra um prego, vira ele de ponta pra riba para que espete o pé do primeiro que passa. Tudo que numa casa acontece de ruim é sempre arte do Saci. Não contente com isso, também atormenta os cachorros, atropela as galinhas e persegue os cavalos no pasto, chupando o sangue deles. 0 Saci não faz maldade grande, mas não há maldade pequenina que não faça.

E segue sua narrativa, comentando o poder da carapuça vermelha, do hábito do cachimbo, das mãos furadas por onde passam pequenas brasas e ainda da peça que pregou no moleque, quando colocou pólvora dentro do próprio cachimbo, que o Saci gostava de usar. Ao começar o estouro foi uma risada só, e o Saci saiu correndo para não voltar por muito tempo. Falou da maldade que é feita na crina dos cavalos e do costume vampiresco de sugar o sangue dos pobres animais. Para evitar isso, usa-se colocar um "bentinho" no pescoço dos mesmos, protegendo-os. Convém explicitar que os bentinhos são escapulários que contêm gravuras de santos, pedaços de tecidos ou orações com o poder de proteção. Têm esse nome porque se benze para dar virtude. É comum encontrar escapulários no pescoço de crianças e mesmo de adultos da zona rural, ou mesmo em carteiras de dinheiro, costuradas a roupas, etc.

0 objetivo de valorização da cultura nacional, que era uma constante em Monteiro Lobato, bem como o seu estudo sobre as personagens do folclore no Brasil, levaram-no a incluir no conto 0 Saci outras figuras do folclore, de conformidade com um dos aspectos de sua obra infantil: o caráter educativo. Aparecem, então, 0 


\section{EMTESE}

Belo Horizonte, v. 8, p. I-243, dez. 2004

Jurupari, o Curupira, a Iara, o Caipora, a Porca-dos-sete-leitões, o Negrinho do Pastoreio, a Cuca, o Boitatá, a mula-sem-cabeça e o Lobisomem. $^{2}$

Lobato, ao destacar o Saci-Pererê e o Jeca Tatu, busca sugerir uma nova mentalidade nacional, e concentra seus esforços na literatura para crianças e jovens, cuja personalidade e caráter encontram-se em formação, e que pelo conhecimento mais apurado do povo e de seus costumes, poderia, mais tarde, elaborar projetos destinados à modernização e desenvolvimento do Brasil, calcados em bases nacionais e populares. Esta modernização traz implícita a característica do dinamismo, entendido como capacidade de adaptação e criação de novos valores e novos padrões culturais, para conviverem com novos tempos e situações.

Monteiro Lobato não fez apenas um registro da tradição oral mas, através do Saci, estabeleceu uma ponte entre o mundo da razão e as superstições e costumes próprios do povo, convidando-nos a uma reflexão sobre os elementos de resgate desse mito brasileiro, bem nacional. Procurar conhecer nossas lendas, mitos e costumes é uma forma de caminharmos para a independência cultural, ao invés de copiar e absorver passivamente os valores estrangeiros. Ao mesmo tempo é compreender que o Brasil possui elementos culturais próprios que, da mesma forma que nos individualizam, ligam-nos a todos os povos e países do mundo. Por outro lado, conhecer o povo é adquirir condições e criar formas de educá-10. É possibilitar sua projeção para o futuro.

Monteiro Lobato, com o Jeca Tatu, o Saci-Pererê e exemplos da Cultura Popular e do Folclore, pretendeu acordar o povo brasileiro do seu estado de inércia, de inoperância, incitando-o à luta, a que ele próprio se entregou durante toda a sua vida. Uma luta em favor do "ressurgimento brasileiro de todos nós". Seu combate legou à posteridade o exemplo de um homem que amou o Brasil como poucos, batalhando por sua terra e seu povo, legando aos brasileiros o tesouro de sua produção literária. Mostrou a todos o Saci-Pererê, que segundo as palavras do próprio escritor, é "pano de amostra, revelador de que esta terra tem uma alma". 
NOTAS :

1. Chevalier, Jean; GHeERBRAnt, Alain. Dicionário de Símbolos. 2. ed. Trad. Vera da Costa e Silva et. alii. Rio de Janeiro: José 0lympio Editora, 1990, p. 945. Dioniso (Baco), deus do vinho, era filho de Júpiter e de Sêmele. Não representava apenas o poder embriagador do vinho, mas também suas influências benéficas e sociais, de maneira que era tido como o promotor da civilização, legislador e amante da paz.

2. Informações sobre as personagens folclóricas podem ser encontradas, em sua maioria, em Luís da Câmara Cascudo, nos livros: Dicionário do Folclore Brasileiro e Geografia dos Mitos Brasileiros.

ABSTRACT :

This work intends to emphasize the inquiry realized by Monteiro Lobato through the newspaper 0 Estado de São Paulo which was published in 1918 with the title "0 SacyPererê - resultado de um inquerito". Besides, the work intends to focus on Saci's myth which is privileged by Lobato in his work by attracting attention of the Brazilians to Brazil's cultural roots and preserving its identity. This work has spread to juvenile public with a publication of 0 Saci, in 1921, which is inscribed in Sitio do Picapau Amarelo.

KEY WORDS: Monteiro Lobato, saci, culture, caboclo.

\author{
REFERÊNCIAS BIBLIOGRÁFICAS
}

CASCUD0, Luis da Câmara. Dicionário do Folclore Brasileiro. 7. ed. Belo Horizonte: Editora Itatiaia Ltda, 1988.

CASCUDO, Luis da Câmara. Geografia dos Mitos Brasileiros. Belo Horizonte: Editora Itatiaia, 1983.

CHEVALIER, Jean; GHEERBRANT, Alain. Dicionário de Símbolos. $2^{a}$ ed. Trad. Vera da Costa e Silva et alii. Rio de Janeiro: José 0lympio Editora, 1990.

LOBAT0, José Bento Monteiro. Urupês. 11. ed. São Paulo: Editora Brasiliense, 196.

LOBATO, José Bento Monteiro. O Sacy-Pererê - resultado de um inquérito. Edição fac-similar. Rio de Janeiro: Gráfica J. B. S/A, 1998.

LOBAT0, José Bento Monteiro. O Saci. São Paulo: Editora Brasiliense, 1973.NUNES, Cassiano. O sonho brasileiro de Lobato. Rio de Janeiro: Gráfica 01 impica Editora Ltda, 1979. 